\title{
Milk Production Change Following Clinical Mastitis and Reproductive Performance Compared Among J5 Vaccinated and Control Dairy Cattle
}

\author{
D. J. Wilson, ${ }^{* 1}$ Y. T. Grohn, † G. J. Bennett, † R. N. González,† Y. H. Schukken, $†$ and J. Spatzł \\ *Department of Animal, Dairy and Veterinary Sciences, Utah State University, Logan 84321 \\ †Department of Population Medicine and Diagnostic Sciences, Cornell University, Ithaca, NY 14850 \\ $\ddagger$ The Animal Health Centre, Te Aroha, New Zealand, 3320
}

\section{ABSTRACT}

Naturally occurring cases of bovine clinical mastitis (CM) were studied among J5 vaccinates and controls on 3 commercial dairy farms. Milk production change and reproductive performance following $\mathrm{CM}$ were compared between the 2 groups. Among 306 controls and 251 vaccinates, there were 221 new cases of CM affecting 120 cows; 437 lactations never had a case of CM. Environmental pathogens made up 90\% (159/176) of etiologic agents isolated. Change in daily milk production following CM was associated with J5 vaccination, days in milk (DIM) at onset of CM, and herd effect as well as each 2-way interaction between the 3 factors. The adjusted daily milk for $21 \mathrm{~d}$ following CM was $7.6 \mathrm{~kg}$ greater among J5 vaccinates than controls; however, this protective effect of vaccination waned with increasing DIM at onset of CM. A mixed linear model with autoregressive order 1 [AR(1)] correlation structure estimated the daily milk production of any cow (whether or not she had CM) on a given DIM. Cows with CM caused by nonagalactiae streptococci, Staphylococcus aureus, Escherichia coli, or Klebsiella lost significant daily milk production for the entire lactation relative to nonmastitic cows. Another mixed linear model for only coliform CM cases (E. coli, Klebsiella, and Enterobacter) within the first 50 DIM showed milk loss for $21 \mathrm{~d}$ following coliform CM to be significantly less for J5 vaccinates than for controls, by 6 to $15 \mathrm{~kg}$ per day. Cows were significantly less likely to become pregnant if they had CM caused by $E$. coli ( $42 \%$ pregnant) or Streptococcus spp. (38\% pregnant), whereas $78 \%$ (342/437) of cows with no mastitis conceived. Days open (number of days from calving until pregnancy) averaged $131 \mathrm{~d}$ for cows with no CM and $162 \mathrm{~d}$ for cows that had at least one case of CM. Days until conception, days until last breeding, days open, times bred,

Received May 30, 2008.

Accepted July 26, 2008.

${ }^{1}$ Corresponding author: David.Wilson@usu.edu and percentage of cows pregnant by 200 DIM were not changed with J5 vaccination. Nonetheless, an important benefit of the use of J5 bacterin appears to be reduction of the loss of daily milk production following $\mathrm{CM}$, whether all cases or only those caused by coliform bacteria were considered.

Key words: bovine mastitis, dairy cattle, immunology, J5 vaccination

\section{INTRODUCTION}

Coliform mastitis continues to increase in importance as a disease complex of dairy cattle, caused by Escherichia coli, Klebsiella, Enterobacter, and Citrobacter IMI. In addition to effects such as abnormal milk, treatment costs, and death of cattle, milk production loss often follows clinical mastitis (CM), including coliform mastitis (Fuquay et al., 1975; Jackson and Bramley, 1983; Jones and Ward, 1989; Wenz et al., 2001). Increased pregnancy loss has also been reported in association with CM (Chebel et al., 2004), as has reduced conception rate (Schrick et al., 2001; Maizon et al., 2004; Santos et al., 2004). Decreased reproductive performance including increased services per conception has also been reported in association with CM (Barker et al., 1998). In contrast, a retrospective analysis of 70 published papers suggested no effect on reproduction associated with mastitis (Fourichon et al., 2000). For more than $15 \mathrm{yr}$, vaccines against the J5 core antigen of coliform bacteria have been used in dairy cattle (González et al., 1989; Cullor, 1991). Associations between J5 vaccination and various measures of clinical severity of CM have been studied infrequently for naturally occurring cases of CM. Reduction of CM in vaccinates compared with controls has been reported as 70\% (Cullor, 1991), 80\% (González et al., 1989), and 72\% (González et al., 1996), which may result in less milk production loss following CM. Associations between J5 vaccination and milk production change and reproductive performance indices following naturally occurring cases of CM have not been reported previously. 


\section{MATERIALS AND METHODS}

Three commercial dairy farms milking Holstein cattle in New York State participated in the study. Mean herd sizes were 275, 330, and 630 lactating cows, referred to herein as herds A, B, and C, respectively. All herds had milk production of approximately $11,400 \mathrm{~kg}$ per cow per lactation. All 3 farms milked cows in fully automated milking parlors with good milking methods. Bulk tank milk SCC were consistently less than 250,000 cells $/ \mathrm{mL}$, and contagious mastitis was well controlled. Historical milk culture data showed that the herds had predominantly environmental types of IMI before the study began. The herds were described in detail in a previous report (Wilson et al., 2007).

\section{Criteria for Inclusion in Study}

Cows meeting the following criteria were included in the 20-mo study: had completed at least one previous lactation; had a dry period length between 45 and $75 \mathrm{~d}$; each of the last 3 monthly individual-cow SCC were $<1,000,000 / \mathrm{mL}$; and no detectable illness at time of dryoff. Assignment to the J5 vaccinate or control group was by randomization within blocks of 10 cows. Mature-equivalent milk production for each cow was within $10 \%$ of the mean $305-\mathrm{d}$ mature-equivalent yield for the block. The J5 vaccine (Merial Ltd., Duluth, GA) was administered by the investigators subcutaneously $(2 \mathrm{~mL})$ in the supramammary lymph node region just before cows were dry and again 21 to $28 \mathrm{~d}$ before the calving due date, during the mid-dry period. Control cows did not receive any sham vaccination.

\section{Exclusion of Some Initially Enrolled Animals}

There were 711 cows enrolled at the beginning of their dry period (374 controls and 337 vaccinates). Reasons for loss or exclusion of 68 controls and 86 vaccinates from the study were reported earlier (Wilson et al., 2007). Briefly, cows were excluded because of milk samples or blood samples required by protocol not collected, vaccinates not given their second vaccination, death, abortion, culling, poor disease records, or dry period $<45$ or $>75 \mathrm{~d}$, which could only be determined after calving.

All cases of CM that occurred during the first 200 DIM or until the cow was confirmed pregnant were included. Cows were monitored for whether they were sold, died, or completed lactation. Some cows had multiple CM episodes in the same quarter over time. Any such episode that occurred within $5 \mathrm{~d}$ of the end of treatment (or end of milk withholding), or any episode from 6 to $14 \mathrm{~d}$ after recovery from the earlier episode with the same etiologic agent isolated from both episodes was considered a chronic case of mastitis. If a different mastitis pathogen was isolated or the episode occurred more than $14 \mathrm{~d}$ after recovery, it constituted a new CM case. Chronic CM cases were excluded from analysis because, when results were compiled, there were only 9 chronic cases out of 230 cases of CM (3.5\%).

\section{Measurement Validation and Standardization}

Accuracy of computerized daily milk weight recording was evaluated on all 3 study farms. Each cow's ID and daily milk weight were recorded manually in the milking parlor during milking and then compared with the computer-generated list of cows and their daily milk weights. On 2 farms, 97\% of all cows' milk weights were recorded correctly in the computer data, but inaccuracy was approximately $30 \%$ on multiple verifications of milk weights on the third farm. Only daily milk weights from the 2 accurate farms (with 330 and 630 lactating cows) were used in the production loss calculations.

Training and standardization for CM detection, use of a cow-side scale for clinical severity, and aseptic sample collection was provided to milking personnel at the beginning of the study. Clinical mastitis severity was scored as $1=$ abnormal milk, normal quarter; $2=$ abnormal milk, mild quarter swelling; $3=$ abnormal milk, severe quarter swelling; $4=$ abnormal milk and cow showed signs of systemic illness (off feed, fever, depression, or sunken eyes). Microbiological methods for identification of intramammary pathogens were described earlier (Wilson et al., 2007).

\section{Production, Disease, and Reproduction Information}

Herd, cow ID, lactation number, daily milk production throughout lactation, and DIM at onset of each new case of CM were recorded for all cows and stored in Dairy Comp 305 (Valley Agricultural Software, Tulare, CA). Mean milk production for the $14 \mathrm{~d}$ before onset of CM, mean milk production for the $21 \mathrm{~d}$ after the end of treatment for CM (or after onset if there was no treatment), and the resultant difference in milk production change before and after each case of $\mathrm{CM}$ was calculated. Quarter(s) with $\mathrm{CM}$ and clinical severity scores were recorded on paper forms at the farm. Mastitis pathogens isolated were recorded at the Quality Milk Production Services Central Laboratory (Ithaca, NY). Total times bred, date of each breeding, DIM at conception for pregnant cows, days open for cows not pregnant until they ended lactation or were sold or died, and abortions were recorded for all cows and stored in Dairy Comp 305. Services per conception, 
percent of cows pregnant by 150 DIM, and percent of cows pregnant by 200 DIM were calculated.

\section{Statistical Analysis}

Statistical analyses including chi-square, ANOVA, linear regression (PROC GLM), survival (time to event) analysis methods (PROC LIFETEST, PROC PHREG), and linear mixed models with an autoregressive (1) [AR(1)] correlation structure (PROC MIXED) were performed using SAS software version 8.2 (SAS Institute, Cary, NC). For comparison of milk production change between controls and J5 vaccinates following CM, only the population of cows with CM could be tested. For comparison of reproductive performance among controls and J5 vaccinates, and for evaluation of factors affecting daily milk production regardless of $\mathrm{CM}$, the entire population of study cows was tested. Differences between the groups for becoming pregnant (whether cows became pregnant or never became pregnant at any time during lactation) as well as whether or not they were pregnant by 150 DIM and by 200 DIM were evaluated with the chi-square test. Times bred was tested as a continuous variable with ANOVA to compare between the controls and vaccinates. Evaluation of days open for all cows (whether they eventually became pregnant or not), as well as days until conception (cows that became pregnant only), and days until last breeding (for all cows that were bred at least once) used survival (time to event) analysis to compare vaccinates and controls. Cows that never were bred or never became pregnant were right censored by leaving the herd or ending lactation.

The Kaplan-Meier method (PROC LIFETEST) estimates the survival curve using a multiplicative function of the probability that the event of interest occurs within a time interval at a time greater than or equal to the start time of each interval. The survival curves are then compared between vaccinates and controls and the difference in survival is statistically tested using the log-rank test. For example, the initial survival analysis (PROC LIFETEST) for factors associated with time until pregnancy or censoring (days open) was $\mathrm{h}(\mathrm{t})$ $=$ VACC.

The initial Cox's proportional hazards model (PROC PHREG) tested was

$$
\begin{gathered}
\mathrm{h}(\mathrm{t})=\mathrm{h}(0) \text { EXP (VACC + LACT + MAST } \\
+ \text { HERD + PRODDIFF + PREMEAN + SEVERITY } \\
+ \text { PATHOGEN + BOOSTTODUE } \\
+ \text { BOOSTTOCALVE })
\end{gathered}
$$

where $h(t)=$ probability of conception within time $t$ for cows not pregnant at beginning of $t ; h(0)$ is a baseline hazard function; EXP (VACC + LACT + MAST + ...) is a linear function of a set of fixed covariates, which are exponentiated; $\mathrm{VACC}=\mathrm{J} 5$ vaccinate or control; $\mathrm{LACT}=$ lactation number 2, 3, or 4+; MAST = never got CM (0) or contracted one or more cases of CM (1); PRODDIFF $=$ mean milk production during $14 \mathrm{~d}$ before CM onset (PREMEAN) subtracted from mean milk production $21 \mathrm{~d}$ following end of treatment following CM (POSTMEAN) (e.g., if PREMEAN $=45 \mathrm{~kg} / \mathrm{d}$ and POSTMEAN $=41 \mathrm{~kg} / \mathrm{d}$, PRODDIFF $=-4 \mathrm{~kg}$, SEVERITY $=4$ levels of cow-side severity of CM described earlier; PATHOGEN = etiologic pathogen isolated from CM, including negative or no case; BOOSTTODUE $=\mathrm{d}$ from $\mathrm{J} 5$ booster to due date of expected calving; and BOOSTTOCALVE = d from J5 booster to date of actual calving.

Milk production following CM was evaluated in 2 ways. The first method evaluated the outcome variable as PRODDIFF (described above), the difference between the mean milk production for $14 \mathrm{~d}$ before $\mathrm{CM}$ onset and for $21 \mathrm{~d}$ following end of treatment. This method has been described previously (Bartlett et al., 1991; Wilson et al., 1991a,b). The initial general linear model (PROC GLM) testing for factors associated with milk production change (PRODDIFF) following CM was $\mathrm{Y}=\mathrm{VACC}+e$, and the expanded model with other covariates (potential explanatory variables) was

$$
\begin{gathered}
\text { Y = VACC + DIM + HERD + LACT + PREMEAN } \\
+ \text { SEVERITY + PATHOGEN + BOOSTTODUE } \\
\text { + BOOSTTOCALVE + } e,
\end{gathered}
$$

where $\mathrm{Y}=$ PRODDIFF, DIM $=$ DIM at onset of CM, and $e=$ unexplained variation. Other variables are defined above.

The second method of evaluating milk production change after CM was to model the outcome variable as the daily milk production of any cow on a given day of lactation. Covariates included whether this day was from $14 \mathrm{~d}$ before CM onset through $21 \mathrm{~d}$ after the end of treatment (specific values from -14 to +21 ). Daily milk weights of all cows including those not contracting any $\mathrm{CM}$ were also included to help model the lactation curve. The use of linear mixed models with an AR(1) correlation structure was chosen because this had earlier been found by the authors to be the best method to model the outcome of daily milk production on any particular day of lactation (Wilson et al., 2004). The initial linear mixed model (PROC MIXED) testing for factors associated with milk production of any cow on a given day in lactation was 


$$
\begin{gathered}
\text { Y = VACC + DIM1 + DIM2 + HERD + LACT } \\
+ \text { PATHOGEN + DAYSRTMAST + BOOSTTODUE } \\
+ \text { BOOSTTOCALVE + COW }(\text { RANDOM })+e,
\end{gathered}
$$

where $\mathrm{Y}=$ MILKPERDAY; DIM1 = DIM/305; and DIM2 $=\log (305 / \mathrm{DIM})$; transformations of DIM to model the milk production lactation curve (Schaeffer et al., 2000) (with DIM = DIM of lactation that day, not at onset of CM); LACT = lactation number 2 through 9 (LACT was not consolidated into $4+$ for this analysis); DAYSRTMAST $=$ number of days that that particular day is removed from the onset day of a case of CM from -14 to $+21 \mathrm{~d}$, or a baseline value if not within that time range or that cow never contracted CM; COW (RANDOM $)=$ random effect of cow, using an AR(1) autocorrelation structure to adjust for correlation between different milk weights from the same cow over time; and $e=$ unexplained variation. Other variables are defined above.

Two other linear models for daily milk production were constructed: one for only CM cases that occurred within the first 50 DIM of lactation along with control cows that never contracted CM, and one for only coliform (E. coli, Klebsiella, and Enterobacter) cases of CM in the first 50 DIM along with nonmastitic controls.

\section{RESULTS}

During the study period of $606 \mathrm{~d}$, the study population comprised 557 lactations: 306 controls and 251 vaccinates. Clinical mastitis was contracted at least once during 120 study lactations (1 of 119 cows to contract CM completed 2 study lactations, and contracted $\mathrm{CM}$ in both lactations): 59 controls and 61 vaccinates. There were 437 lactations without a case of CM, comprising 247 controls and 190 vaccinates. The 120 cows with at least one case of CM contracted 221 new cases of CM. Detailed analysis of CM among vaccinates and controls was reported earlier (Wilson et al., 2007).

\section{Mastitis Pathogens and CM Incidence}

A milk culture sample was collected from 204 of the 221 new cases of CM (99 controls and 105 vaccinates). Mastitis pathogens are shown in Table 1. For all pathogens, isolation from the $204 \mathrm{CM}$ cases cultured was not different among vaccinates and controls $(P=0.23$, chisquare). Infection rate for the 221 new cases of CM was 0.55 cases/200 DIM or 0.08 cases/30 DIM. Detailed descriptive epidemiology including cumulative incidence and cows with subsequent new cases of CM during lactation was reported earlier (Wilson et al., 2007).
Table 1. Etiologic agents of 204 clinical mastitis cases among J5 vaccinates $(n=251)$ and controls $(n=306)$

\begin{tabular}{lcc}
\hline & \multicolumn{2}{c}{ Vaccination status ${ }^{1}$} \\
\cline { 2 - 3 } Pathogen & $\begin{array}{r}\text { J5 vaccinate } \\
(\mathrm{n}=105)\end{array}$ & $\begin{array}{c}\text { Controls } \\
(\mathrm{n}=99)\end{array}$ \\
\hline No pathogen isolated & 10 & 18 \\
Escherichia coli & 27 & 15 \\
Klebsiella & 8 & 13 \\
Streptococcus spp. & 26 & 26 \\
Staphylococcus aureus & 9 & 8 \\
CNS & 6 & 7 \\
Arcanobacterium pyogenes & 7 & 4 \\
Enterobacter & 3 & 0 \\
Yeast & 1 & 2 \\
Gram-positive bacilli & 2 & 0 \\
Fungi & 1 & 0 \\
Mixed pathogens & 5 & 6 \\
\hline
\end{tabular}

${ }^{1}$ No significant differences between $\mathrm{J} 5$ vaccinates and controls in distribution of mastitis pathogens, chi-square, $P=0.23$.

\section{Reproductive Performance and J5 Vaccination}

Percentage of cows that became pregnant was $71.5 \%$ for all cows (398/557), 73.5\% for controls (225/306), and $68.9 \%$ for J5 vaccinates (173/251), and was not significantly different $(P=0.23$, chi-square) among groups. Mean and median, respectively, for DIM at conception were 124.9 and 103 for controls and 134.3 and 114 for vaccinates, and for days open (whether cows became pregnant or not) were 133.8 and 104.5 for controls and 140.9 and 117 for vaccinates. Survival (time to event) analysis showed that DIM at conception $(P=0.26$, logrank and Wilcoxon tests) and days open $(P=0.27$, logrank; $P=0.16$, Wilcoxon test; PROC LIFETEST) were not different between controls and J5 vaccinates. Because the results of analysis of the 3 outcome variables DIM at conception (pregnant cows only), time until last breeding (cows bred at least once whether became pregnant or not), and days open (for all cows including those not becoming pregnant) were all similar, only analysis of days open is further reported.

Percentage of cows pregnant by 150 and 200 DIM was evaluated. Of the 306 control cows, 165 (53.9\%) became pregnant by 150 DIM, whereas 111/251 (44.2\%) of J5 vaccinates became pregnant, significantly fewer among the vaccinates $(P=0.02$, chi-square). By 200 DIM, 197 controls (64.4\%) became pregnant and 144 vaccinates (57.4\%) did, which was no longer different among the groups $(P=0.09$, chi-square).

Times bred ranged from 0 to 10 , with a mean of 2.2 for all cows. Times bred averaged 2.2 for controls and 2.3 for vaccinates, which was not significantly different $(P=0.70$, ANOVA). Similarly, services per conception averaged 2.5 for the 225 controls and 2.6 for the 173 


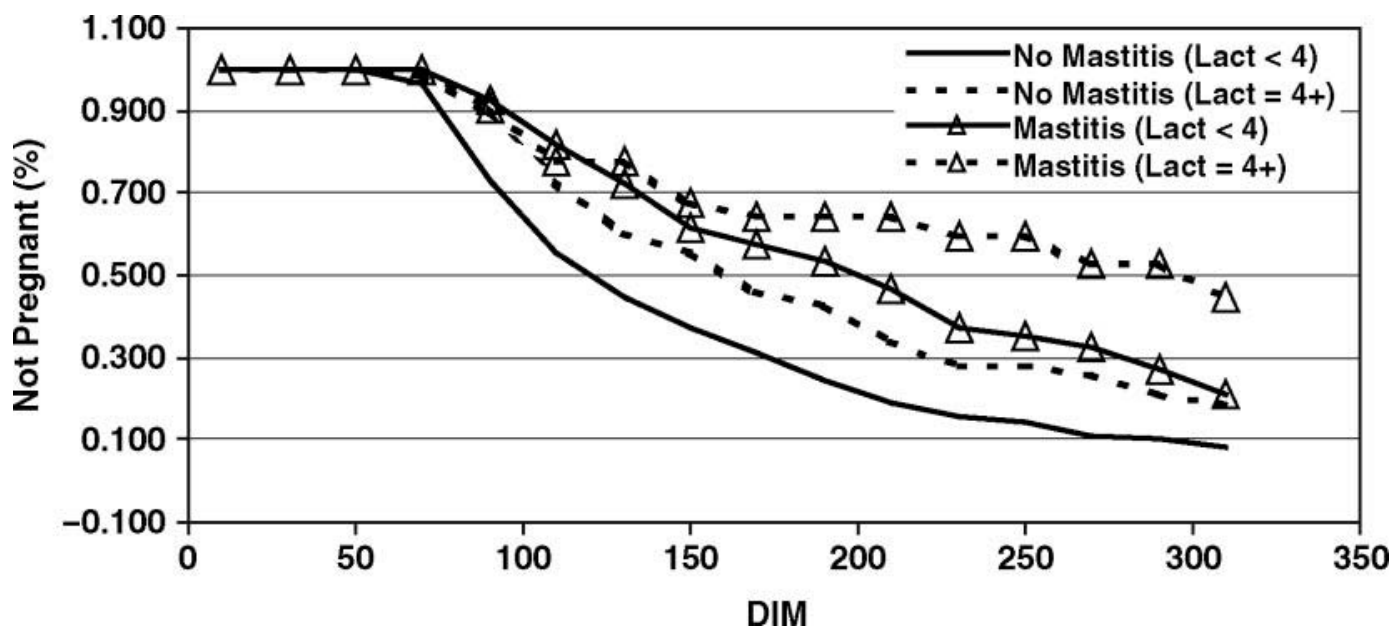

Figure 1. Percentage of cows not yet pregnant (still open) with increasing DIM. Significantly greater days open until pregnant for cows with clinical mastitis and in lactation 4+ were observed relative to cows in lactation 2 or 3 without mastitis. All lines shown were significantly different from each other. Time to event analysis, log-rank, and Wilcoxon tests, $P<0.0001$.

vaccinates that became pregnant, which was not different $(P=0.40$, ANOVA $)$.

\section{Other Factors Associated with Reproductive Performance}

Other factors, including CM, affected reproductive performance. Among the 120 cows that contracted CM, 56 cows became pregnant (46.7\%), whereas 342 of the 437 cows with no CM became pregnant (78.3\%; $P<0.0001$, chi-square). There was no difference in pregnancy between J5 vaccinates $(151 / 190=79.5 \%$ pregnant) and controls (191/247 $=77.3 \%$ pregnant $)$ among the 437 cows that never had CM $(P=0.59$, chi-square). However, among the cows that did have CM, 34/59 controls (57.6\%) became pregnant, whereas $22 / 61$ vaccinates $(36.1 \%)$ became pregnant, which was a significant difference $(P=0.02$, chi-square). Specific CM pathogens associated with less pregnancy were $E$. coli $(41.7 \%$ pregnant; $P=0.001)$ and Streptococcus spp. (37.5\% pregnant; $P<0.0001)$. Among control cows, $E$. coli $\mathrm{CM}$ did not reduce pregnancy $(8 / 12=66.7 \%$ pregnant; $P=0.58)$, but among vaccinates, it $\operatorname{did}(2 / 12=$ $16.7 \%$ pregnant; $P<0.0001$ ). Clinical mastitis caused by Streptococcus spp. was equally likely to reduce pregnancy among controls and vaccinates (37.5\% pregnant in both categories). Of the 132 cows with $\geq 4$ lactations, $66(50 \%)$ became pregnant, whereas 332 of the 425 cows in second or third lactation $(78.1 \%)$ conceived $(P<$ 0.0001). The herds did not differ in percentage of cows becoming pregnant, with all 3 having between 71.1 and $71.7 \%$ of cows becoming pregnant $(P=0.99)$.

Risk factors associated with days open were evaluated using survival (time to event) analysis. Mean days open for all cows was $136.9 \mathrm{~d}$. Cows with $\geq 4$ lactations or that contracted at least one case of CM were open longer than other cows $(P<0.001$, likelihood ratio chisquare, PROC PHREG; Figure 1). Days open means were 130.5 for cows with no CM, 162.3 for cows that had $\mathrm{CM}$ at least once, 134.2 for cows in lactations 2 or 3 , and 145.8 for cows with $\geq 4$ lactations. Vaccination with J5 was not associated with days open $(P=0.35$, likelihood ratio chi-square).

Services per conception averaged 2.6 for all cows and was different between herds. The 3 herds averaged $2.2,2.6$, and 3.0 services per conception, which was significantly different $(P<0.03$, type 3 SS F test, linear regression, PROC GLM). Cases of CM caused by $E$. coli $(P=0.04$, Type $3 \mathrm{SS} F$ test, linear regression) and Klebsiella $(P=0.02)$ were also significantly associated with increased services per conception, with means of 3.6 and 3.8, respectively. There was no interaction between $\mathrm{CM}$ and herd, and vaccination with J5 did not influence the effects of CM or herd on services per conception $(P=0.22)$. One herd had a significantly lower percentage of cows pregnant by 150 DIM $(40 \%)$ and by 200 DIM $(52 \%)$ than the other herds $(P<0.05$, chi-square). Vaccination with J5 did not interact with this herd effect ( $P>0.70$, chi-square).

\section{Milk Production Loss and J5 Vaccination}

Mean daily milk production difference from $14 \mathrm{~d}$ before CM onset to $21 \mathrm{~d}$ following end of treatment for CM (PRODDIFF) was evaluated. Of the 166 new cases of CM, 37 cases did not have any daily milk production recorded either before the onset of $\mathrm{CM}$ or after the end of treatment. Another 37 cases were in the herd that 
Table 2. Linear regression model significant factors associated with change in daily milk production from 14 $\mathrm{d}$ before onset of clinical mastitis (CM) to $21 \mathrm{~d}$ following end of treatment (PRODDIFF)

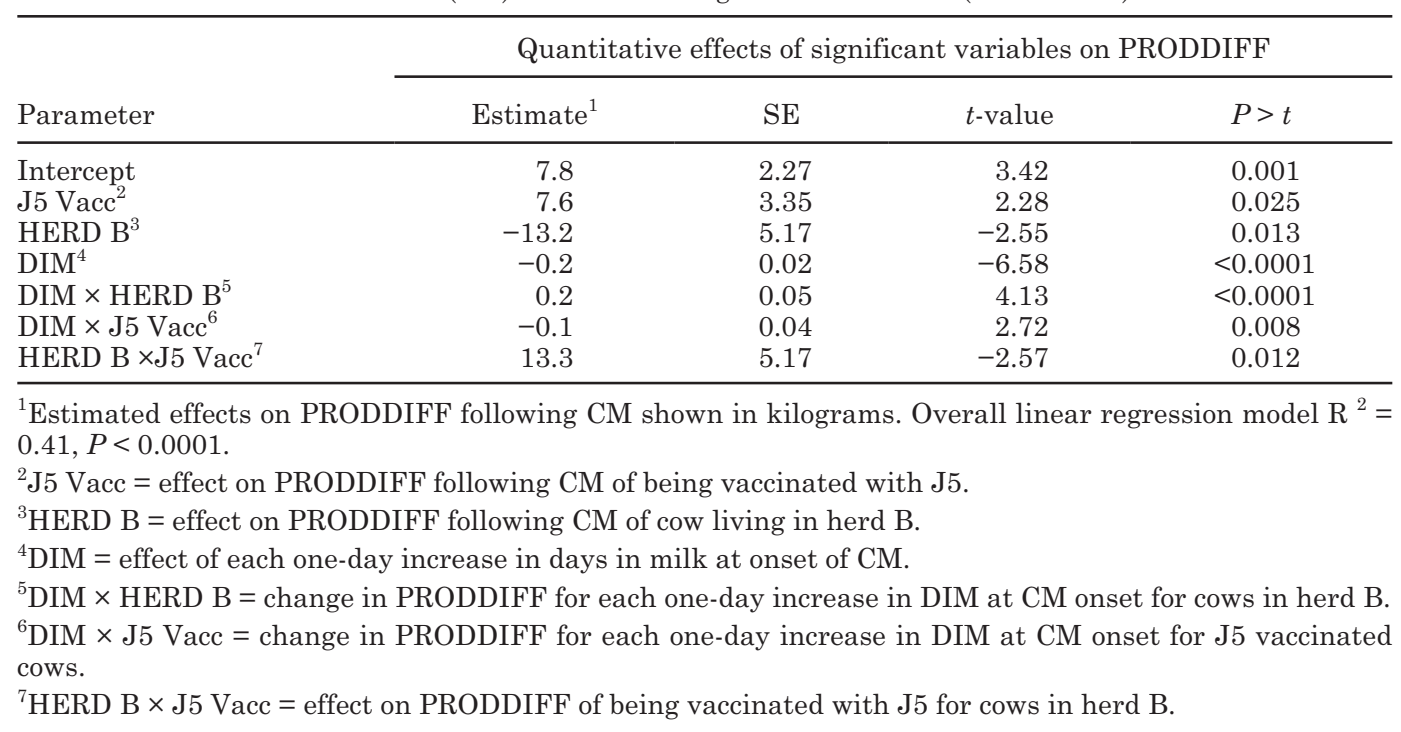

was excluded because of inaccurate daily milk weights. Therefore, 92 cases were evaluated for PRODDIFF following CM. Most cows lost milk following CM; mean PRODDIFF was $5.5 \mathrm{~kg}$. For 38 controls, PRODDIFF was $-6.6 \mathrm{~kg}$, and for 54 vaccinates, it was $-4.7 \mathrm{~kg}$, which was not significantly different $(P=0.35$, ANOVA).

Factors associated with PRODDIFF in addition to J5 vaccination, adjusting each factor for the effects of the others, were tested using linear regression. The final linear model (PROC GLM) of significant factors included J5 vaccination, DIM at onset of CM, herd, and each of the 2-way interactions between those factors (Table 2).

For all cows, when adjusting for the other significant factors of DIM and herd, there was less (by $7.6 \mathrm{~kg}$ ) mean daily milk loss as a main effect for J5 vaccinates than for controls $(P=0.03$, type $3 \mathrm{SS} F$ test, linear regression, PROC GLM; Table 2). As CM onset occurred later in lactation, more milk was lost $(0.2 \mathrm{~kg}$ of PRODDIFF loss for each day of increased DIM at onset of CM; $P$ $<0.0001)$. There was a substantial herd effect: cows in herd B lost more PRODDIFF following CM in early lactation but this effect was mostly present in controls and not in vaccinates (interaction term of herd $B$ and J5 in Table 2). However, there was considerable milk loss for controls relative to $\mathrm{J} 5$ vaccinates in both herds in early lactation. With increasing DIM, the beneficial effect of J5 vaccination waned and disappeared at approximately 100 DIM. Lactation number, pathogen isolated at onset of CM, clinical severity, and time from booster immunization to due date or actual calving date were not significantly associated with PRODDIFF following CM (all $P>0.20$ ).

\section{Daily Milk Production and Mastitis, J5 Vaccination, and Other Factors}

Factors significantly associated with daily milk production of any cow (including those never contracting $\mathrm{CM}$ ) on a given day were tested using $\mathrm{AR}(1)$ correlation structure using a mixed linear model. Significant factors were herd, DIM1, DIM2 (transformations of DIM of lactation, not of onset of CM), lactation number, etiologic pathogen of CM, DAYSRTMAST (between $-14 \mathrm{~d}$ from onset of $\mathrm{CM}$ and $+21 \mathrm{~d}$ from end of treatment for $\mathrm{CM}$, with baseline value if outside that time range from $\mathrm{CM}$ ), interaction of DIM2 with herd, and the separate interaction of J5 vaccination with herd [all $P<0.003$, type $3 \mathrm{~F}$ test, mixed linear model (PROC MIXED)]. Cows that contracted CM were not significantly different from other cows in daily milk production for the last week before onset of CM except at $2 \mathrm{~d}$ before onset (all $P>0.05, t$-test, mixed linear model, except $-2 \mathrm{~d}$, Table 3). From the day of onset of CM through $21 \mathrm{~d}$ after end of treatment, mastitic cows lost milk production. Losses were approximately $8 \mathrm{~kg} / \mathrm{d}$ for $\mathrm{d} 0$ and 1 , from 2 to $5 \mathrm{~kg} / \mathrm{d}$ from d 2 to 16 , and $1 \mathrm{~kg}$ from d 17 to 21 (all $P \leq 0.01, t$-test, mixed linear model; Table 3). Cows with etiologic pathogens Streptococcus spp. (-3.3 $\mathrm{kg})$, Staphylococcus aureus $(-4.2 \mathrm{~kg})$, E. coli $(-1.6 \mathrm{~kg})$, and Klebsiella $(-4.9 \mathrm{~kg})$ all lost significant daily milk production for the entire lactation when adjusting for the other significant factors (all $P<0.04$, Table 3).

Cows in lactations 2 and 4 produced similar amounts of daily milk ( $P=0.81, t$-test, mixed linear model), but they produced more milk than cows in lactation 3 (0.6 kg; $P=0.01$ ), and considerably more daily milk than 
older cows. Cows in lactations 5 (2.4 kg less than lactation 2$)$ through 9 (7.0 kg less than lactation 2$)$ produced progressively less daily milk with age (all $P<0.001$, Table 3).

Cows in herd B produced more daily milk $(+5.3 \mathrm{~kg} ; P$ $<0.0001, t$-test, mixed linear model), but this production advantage decreased as DIM increased (negative interaction of DIM $2 \times$ herd B; $P<0.003$; Table 3). In J5 vaccinates, the advantage for herd $B$ in daily production was reduced by $3.4 \mathrm{~kg}$ (negative interaction of $\mathrm{J} 5$ Vacc $\times$ HERDB, $P<0.0001$; Table 3 ).

Another model was tested for only cases of CM with onset during the first $50 \mathrm{~d}$ of lactation (and cows that never contracted $\mathrm{CM}$ ); results were similar to the model for all cows. However, for CM cases in first 50 DIM, there was a significant interaction between J5 vaccination and milk loss with different pathogens (i.e., J5 Vacc $\times$ PATHOGEN was a significant covariate for $\mathrm{Y}=$ MILKPERDAY; $P=0.04$, Type $3 \mathrm{~F}$ test, mixed linear model). For cows with CM caused by Klebsiella, vaccinates had greater daily milk production than controls during the entire lactation $(+2.3 \mathrm{~kg} ; P=0.04, t$-test, mixed linear model), and cases caused by $E$. coli had greater daily production throughout lactation among vaccinates that approached significance $(+1.8 \mathrm{~kg} ; P=$ $0.10)$.

Another mixed linear model for daily milk production included only coliform CM cases (E. coli, Klebsiella, and Enterobacter) with onset within the first 50 DIM or cows that never contracted CM. Coliforms

Table 3. Parameter estimates, SE, and statistical significance of significant variables from the mixed linear model and their estimated effects on daily milk production of a cow

\begin{tabular}{|c|c|c|c|c|}
\hline Parameter & Estimate $^{1}$ & $\mathrm{SE}$ & $t$-value & $P>t$ \\
\hline Intercept & 66.9 & 0.25 & 122.97 & $<0.0001$ \\
\hline J5 Vacc ${ }^{2}$ & 1.9 & 0.14 & 6.27 & $<0.0001$ \\
\hline HERD B $^{3}$ & 5.3 & 0.19 & 12.49 & $<0.0001$ \\
\hline $\mathrm{DIM}_{1}^{4}$ & -39.9 & 0.31 & -58.13 & $<0.0001$ \\
\hline $\mathrm{DIM} 2^{5}$ & -7.7 & 0.09 & -41.43 & $<0.0001$ \\
\hline Streptococcus spp. ${ }^{6}$ & -3.3 & 0.33 & -4.54 & $<0.0001$ \\
\hline Staphylococcus aureus & -4.2 & 0.53 & -3.66 & 0.001 \\
\hline Escherichia coli & -1.6 & 0.34 & -2.20 & 0.036 \\
\hline Klebsiella & -4.9 & 0.35 & -6.43 & $<0.0001$ \\
\hline LACT $3^{7}$ & -0.6 & 0.11 & -2.55 & 0.001 \\
\hline LACT 5 & -2.4 & 0.25 & -4.48 & $<0.0001$ \\
\hline LACT 7 & -3.6 & 0.45 & -3.64 & $<0.001$ \\
\hline LACT 9 & -7.0 & 0.94 & -3.38 & $<0.001$ \\
\hline \multicolumn{5}{|l|}{ DAYSRTMAST ${ }^{8}$} \\
\hline-3 & 0.6 & 0.27 & 0.93 & 0.350 \\
\hline-2 & 1.9 & 0.27 & 3.32 & 0.001 \\
\hline-1 & -0.4 & 0.26 & -0.64 & 0.523 \\
\hline $0^{9}$ & -7.8 & 0.29 & -12.19 & $<0.0001$ \\
\hline 1 & -8.0 & 0.31 & -11.63 & $<0.0001$ \\
\hline 2 & -4.6 & 0.31 & -6.66 & $<0.0001$ \\
\hline 3 & -3.4 & 0.30 & -5.27 & $<0.0001$ \\
\hline 4 & -3.3 & 0.28 & -5.28 & $<0.0001$ \\
\hline 5 & -2.6 & 0.28 & -4.20 & $<0.0001$ \\
\hline 10 & -2.3 & 0.27 & -3.95 & $<0.0001$ \\
\hline 15 & -2.1 & 0.27 & -3.45 & 0.001 \\
\hline 20 & -0.7 & 0.24 & -1.35 & 0.176 \\
\hline 21 & -1.2 & 0.20 & -2.73 & 0.006 \\
\hline DIM2 $\times$ HERDB $^{10}$ & -0.6 & 0.10 & -3.00 & 0.003 \\
\hline J5 Vacc $\times$ HERDB & -3.4 & 0.23 & -6.85 & $<0.0001$ \\
\hline
\end{tabular}

${ }^{1}$ Estimated effects on milk production shown in kilograms.

${ }^{2} \mathrm{~J} 5$ Vacc $=$ effect of J5 vaccination (part of significant interaction with herd B).

${ }^{3} \mathrm{HERD}=$ commercial dairy herd where cow lived; herd A was baseline.

${ }^{4} \mathrm{DIM} 1=(\mathrm{DIM} / 305)$, a transformation to model shape of lactation curve.

${ }^{5} \mathrm{DIM} 2=\log$ (305/DIM), a companion transformation to model shape of lactation curve.

${ }^{6}$ Etiologic pathogen of CM (no case during lactation was baseline).

${ }^{7} \mathrm{LACT}=$ lactation number (parity); second lactation was baseline.

${ }^{8}$ DAYSRTMAST $=$ days relative to $\mathrm{CM}$ between $-14 \mathrm{~d}$ to $+21 \mathrm{~d}$ (or baseline if that day of lactation is not within that time range).

${ }^{9} 0=$ day of onset of CM.

${ }^{10}$ Interaction of the 2 factors; level of one factor affects the relationship of the other to daily milk production. 
Table 4. Mixed linear model evaluating factors associated with daily milk production for cows with coliform clinical mastitis (CM) contracted during first $50 \mathrm{~d}$ of lactation (or those never contracting $\mathrm{CM}$ ) on a given day

\begin{tabular}{lrrc}
\hline Variable & df & $F$-value & $P>F$ \\
\hline J5 Vacc & & \\
HERD $^{2}$ & 1 & 1.66 & 0.198 \\
DIM1 $^{3}$ & 1 & 163.17 & $<0.0001$ \\
DIM2 $^{4}$ & 1 & $3,291.17$ & $<0.0001$ \\
LACT $^{5}$ & 1 & $1,847.57$ & $<0.0001$ \\
DAYSRTMAST & 6 & 11.11 & $<0.0001$ \\
DIM2 $\times$ HERD $^{7}$ & 36 & 5.15 & $<0.0001$ \\
J5 Vacc $\times$ HERD $^{7}$ & 1 & 9.32 & 0.002 \\
J5 Vacc $\times$ DAYSRTMAST $^{7}$ & 1 & 43.58 & $<0.0001$ \\
\hline
\end{tabular}

${ }^{1} \mathrm{~J} 5$ Vacc $=$ effect of $\mathrm{J} 5$ vaccination is included because part of significant interaction with herd and with days relative to mastitis.

${ }^{2}$ HERD $=$ commercial dairy herd where cow lived.

${ }^{3}$ DIM1 $=(\mathrm{DIM} / 305)$, a transformation to model shape of lactation curve.

${ }^{4} \mathrm{DIM} 2=\log (\mathrm{DIM} / 305)$, a companion transformation to model shape of lactation curve.

${ }^{5} \mathrm{LACT}=$ lactation number (parity); second lactation was baseline.

${ }^{6}$ DAYSRTMAST $=$ days relative to $\mathrm{CM}$ between $-14 \mathrm{~d}$ and $+21 \mathrm{~d}$ (or baseline if that day of lactation is not within that time period).

${ }^{7}$ Interaction of the two factors; level of one factor affects the relationship of the other to daily milk production.

were combined as one pathogen category so there was no variable for pathogen. The interaction of J5 vaccination with the effect on milk production of DAYSRTMAST was significant $(P=0.0002$, type $3 \mathrm{~F}$ test, mixed linear model; Table 4). Milk production during the 21 $\mathrm{d}$ following coliform $\mathrm{CM}$ contracted during the first 50 DIM was significantly greater for J5 vaccinates than for controls.

None of the models for daily milk production described above found the time from booster immunization to due date or actual calving date to be associated with milk production, including that following CM. As shown in Table 5, on most of the $21 \mathrm{~d}$ following coliform CM cases contracted during the first 50 DIM, milk production of J5 immunized cows was at least $6 \mathrm{~kg}$ greater than that for controls, with the difference being as much as $15 \mathrm{~kg}$.

\section{DISCUSSION}

Vaccination with J5 was associated with less milk production loss following CM compared with that of control cows. This became evident and statistically significant only when linear regression or mixed linear models were used to adjust for other significant covariate factors, including a herd effect. Relatively greater milk production among J5 vaccinates following mastitis was especially evident in cases of coliform mastitis with onset during the first $50 \mathrm{~d}$ of lactation.
Table 5. Comparison of mixed model estimated daily milk production between J5 vaccinates and controls before and after coliform ${ }^{1} \mathrm{CM}$ with onset in first $50 \mathrm{~d}$ of lactation (estimates for case at 30 DIM, cow in second lactation, baseline herd)

\begin{tabular}{lccc}
\hline DAYSRTMAST $^{2}$ & DIM & J5 Vaccinates $^{3}$ & Controls $^{3}$ \\
\hline-14 & 16 & 43.8 & 44.2 \\
-3 & 27 & 39.9 & 46.9 \\
-2 & 28 & 41.0 & 44.7 \\
-1 & 29 & 35.7 & 37.2 \\
$0^{4}$ & 30 & 26.6 & 20.7 \\
1 & 31 & 28.5 & 12.8 \\
2 & 32 & 28.6 & 21.5 \\
3 & 33 & 40.6 & 27.5 \\
4 & 34 & 35.5 & 34.8 \\
5 & 35 & 38.7 & 31.9 \\
10 & 40 & 39.5 & 34.8 \\
15 & 45 & 40.7 & 34.4 \\
20 & 50 & 42.4 & 36.0 \\
21 & 51 & 43.5 & 27.9 \\
\hline
\end{tabular}

${ }^{1}$ Coliforms = Escherichia coli, Klebsiella, and Enterobacter .

${ }^{2}$ DAYSRTMAST $=$ days relative to $\mathrm{CM}$ between $-14 \mathrm{~d}$ and $+21 \mathrm{~d}$ (or baseline if that day of lactation is not within that time period).

${ }^{3}$ Estimated milk production shown in kilograms.

${ }^{4} 0=$ day of onset of CM.

Reproductive performance indices were not different between J5 vaccinates and controls. Clinical mastitis and lactation number (parity) $\geq 4$ were associated with increased days open.

When linear regression adjusted for the effects of all significant factors including J5 vaccination, DIM at onset of $\mathrm{CM}$, herd, and each of the 2 -way interactions between those factors, there was nearly $8 \mathrm{~kg}$ more loss in daily mean milk production for $21 \mathrm{~d}$ after treatment ended among control cows than in vaccinates. The results showed that J5 vaccination was a major factor associated with reduced milk loss following CM. Because of the negative interaction term with DIM, the results also suggest that vaccination protection wanes with time since last vaccination. Waning of vaccine efficacy has been described before for both bacterial and viral pathogens (Gomes et al., 2004; De Wals, 2006).

When daily milk production for all cows on a given DIM of lactation was modeled, CM was found to be strongly associated with lower milk production following the disease. Before onset of CM, cows that did or did not eventually contract mastitis were similar in milk production. Other factors affecting daily milk included J5 vaccination, stage of lactation, decreased milk production in older cows, particularly older than fourth lactation, and mastitis caused by Streptococcus spp., Staph. aureus, E. coli, or Klebsiella. It has been recognized previously that stage of lactation (Ferris et al., 1985; Bartlett et al., 1991; Freeze and Richards, 1992; Rajala-Schultz et al., 1999; Wilson et al., 2004), 
age reflected by lactation number (Bartlett et al., 1991; Freeze and Richards, 1992; Rajala-Schultz et al., 1999; Wilson et al., 2004), and mastitis infections with Streptococcus spp., Staph. aureus, E. coli, or Klebsiella (Fuquay et al., 1975; Jackson and Bramley, 1983; Jones and Ward, 1989; Bartlett et al., 1991; Wilson et al., 1997; Wenz et al., 2001) are significant effectors of milk production.

When only cases of mastitis contracted during the first $50 \mathrm{~d}$ of lactation were studied, J5 vaccinates had greater daily milk production than controls during an entire lactation among those cows infected with Klebsiella (approximately $2 \mathrm{~kg}$ ) or $E$. coli (approximately $2 \mathrm{~kg}$ ). For the $3 \mathrm{wk}$ following these coliform cases in early lactation, daily milk production of J5-immunized cows was approximately 7 to $16 \mathrm{~kg}$ greater than that of control cows. There are no previously published field reports regarding naturally occurring cases of CM and milk production following J5 immunization.

Cows in one herd lost significantly more milk production following CM. In this study, in many key characteristics, the herds were quite similar by design. Nevertheless, the results provide a reminder that with J5 vaccine as with many dairy herd management measures, there may be important variation in response among cows in different herds that is not readily explained (Wagter et al., 2000; Santos et al., 2004; Zwald et al., 2004; Caraviello et al., 2005).

Cow-side scale for clinical severity of mastitis was not significantly associated with milk production after CM. This contrasts with one previous report of an intramammary infusion bacterial challenge study that cow-side judgment of clinical signs of CM severity was predictive of milk production loss (Vandeputte-Van Messom et al., 1993). There was no evidence in this study that cows calving early or late, resulting in the second J5 immunization being given earlier or later than 3 or 4 wk from calving, was detrimental to J5 effectiveness. This is a good point of practicality for its use on dairy farms, with the unpredictability of exactly when each cow will calve.

Vaccination with J5 was not associated with reproductive performance: controls and vaccinates did not differ in days open or until breeding, services per conception, or percent of cows pregnant by 200 DIM. However, CM itself had major associations with reproduction. Cows with mastitis were less likely to become pregnant (47\%) than controls (78\%). An earlier study found that $E$. coli J5 LPS administered to Holstein heifers resulted in delayed ovulation by an average of $4 \mathrm{~d}$, but conception was not evaluated (Suzuki et al., 2001). It was reported that in 2 large commercial dairy herds, 397 cases of CM before pregnancy diagnosis were associated with decreased conception, increased abortions, and reduced pregnancy percentage compared with 501 herdmates with no mastitis (Santos et al., 2004).

The pathogens E. coli and Streptococcus spp. were both associated significantly with reduced pregnancy; only approximately $40 \%$ of the cows with those isolates from CM became pregnant. Coliform mastitis has been found associated with relative infertility in dogs (Wendt and Stellmacher, 1996). Cows in lactation $\geq 4$ were less likely to become pregnant (50\%) compared with $78 \%$ of the younger cows. Decreased fertility in dairy cattle older than third lactation has been reported in other studies (Macmillan et al., 1996; Dematawewa and Berger, 1998).

It is not only important whether cows get pregnant, but also how long and how many breedings it takes to get cows pregnant. Among all cows that did get pregnant, survival (time to event) analysis showed that cows that contracted CM had more days until conception (20 d more than cows with no CM). Days open (for all cows including those not becoming pregnant) were also greater for cows in lactation $\geq 4$ or those that contracted CM. Similar results were found for days until last breeding, with $\mathrm{CM}$ and lactation $\geq 4$ associated with greater values by approximately $15 \mathrm{~d}$. Time until cows are first bred or become pregnant has been found to increase with both lactation number (parity) and age (Dematawewa and Berger, 1998) as well as with CM (Schrick et al., 2001; Santos et al., 2004). Nevertheless, a review of 70 papers found that sometimes $\mathrm{CM}$ was associated with increased time to conception, but in most studies, the association was not significant; the review did not discuss specific mastitis pathogens (Fourichon et al., 2000).

Clinical mastitis caused by E. coli or Klebsiella was significantly associated with increased services per conception; vaccination with $\mathrm{J} 5$ did not influence services per conception. A review of 752 Jersey cows with milk culture results from CM cases found that in addition to increased time to first breeding and days open, regardless of pathogen isolated, CM was associated with increased services per conception (2.1 vs. 1.6 in nonmastitic cows; Schrick et al., 2001). Chebel et al. (2004) found that an apparent increase in services per conception following CM was actually due to increased fetal loss shortly after conception among cows with clinical mastitis; the etiologic agent was not determined.

Analyzing milk loss following CM used 2 different methods. Advantages of GLM for PRODDIFF were that it produces one daily milk loss mean number (for milk loss over the $21 \mathrm{~d}$ following $\mathrm{CM}$ ), and the model is simpler and more practical in that the raw milk loss mean can be calculated readily without use of GLM if a dairy producer or herd advisor has access to daily milk weights. A disadvantage of PRODDIFF is that 
each cow is compared only against herself, and there is no lactation curve information from control cows that had no CM.

Advantages of mixed models for MILKPERDAY are that all cows' milk production for all days regardless of $\mathrm{CM}$ can be included, the AR(1) correlation structure to account for correlation of each cow's own milk weights over time is incorporated, and lactation curves can be simulated. (At least that was true in this data set, because the transformations of DIM were more significant in the MILKPERDAY model, whereas only the linear variable DIM was most significant in the PRODDIFF model.) A potential disadvantage of the MILKPERDAY model is that by using the variable DAYSRTMAST for whether that particular day of lactation was between 14 $\mathrm{d}$ before and $21 \mathrm{~d}$ after $\mathrm{CM}, 39 \%$ of that variable (14/36 d) comprised the $14 \mathrm{~d}$ before onset of disease. There would not necessarily be an expected difference in milk production before onset, and indeed, there was not. Therefore, this might hinder the ability of this variable to detect milk production difference by reducing the apparent overall significance of DAYSRTMAST. However, this was not a problem in this study: the model for MILKPERDAY for cases of coliform CM in the first 50 DIM estimated daily loss as $7.0 \mathrm{~kg}$ compared with the PRODDIFF estimate of $7.6 \mathrm{~kg}$.

\section{CONCLUSIONS}

Vaccination with J5 was associated with substantially reduced milk production loss following naturally occurring clinical mastitis compared with that of unvaccinated control cows. This became apparent and statistically significant only when linear regression or mixed linear models adjusted for other significant factors, including herd, stage of lactation, and lactation number (parity). Coliform mastitis cases (E. coli, Klebsiella, and Enterobacter) contracted during the first 50 $\mathrm{d}$ of lactation were most strongly associated with less post-mastitis milk production loss among $\mathrm{J} 5$ vaccinates. Reproductive performance indices were not different between J5 vaccinates and controls, despite that fact that earlier studies as well as the study reported here demonstrated that clinical mastitis can be detrimental to reproduction. Two different methods of estimating milk loss in the $21 \mathrm{~d}$ following clinical mastitis resulted in similar production loss estimates. A major benefit of use of J5 bacterin appears to be reduction of the loss of milk production following clinical mastitis.

\section{ACKNOWLEDGMENTS}

This work was funded by grants from USDA National Research Initiative Competitive Grants Program,
Merial Ltd. (Duluth, GA), and the NYS Centers for Advanced Technology Program (Albany, NY). We appreciate the cooperation of the owners and personnel of the participating dairy farms, and the staff of the Canton Northern Regional Laboratory, the Cobleskill Eastern Regional Laboratory, and the Ithaca Central Regional Laboratory of the Quality Milk Production Services.

\section{REFERENCES}

Barker, A. R., F. N. Schrick, M. J. Lewis, H. H. Dowlen, and S. P. Oliver. 1998. Influence of clinical mastitis during early lactation on reproductive performance of Jersey cows. J. Dairy Sci. 81:1285-1290.

Bartlett, P. C., J. van Wijk, D. J. Wilson, C. D. Green, G. Y. Miller, G. A. Majewski, and L. E. Heider. 1991. Temporal patterns of lost milk production following clinical mastitis in a large Michigan Holstein herd. J. Dairy Sci. 74:1561-1572.

Caraviello, D. Z., K. A. Weigel, G. E. Shook, and P. L. Ruegg. 2005. Assessment of the impact of somatic cell count on functional longevity in Holstein and Jersey cattle using survival analysis methodology. J. Dairy Sci. 88:804-811.

Chebel, R. C., J. E. Santos, J. P. Reynolds, R. L. Cerri, S. O. Juchem, and M. Overton. 2004. Factors affecting conception rate after artificial insemination and pregnancy loss in lactating dairy cows. Anim. Reprod. Sci. 84:239-255.

Cullor, J. S. 1991. The Escherichia coli J5 vaccine: Investigating a new tool to combat mastitis. Vet. Med. 86:836-844.

De Wals, P. 2006. Immunization strategies for the control of serogroup C meningococcal disease in developed countries. Expert Rev. Vaccines 5:269-275.

Dematawewa, C. M., and P. J. Berger. 1998. Genetic and phenotypic parameters for 305-day yield, fertility, and survival in Holsteins. J. Dairy Sci. 81:2700-2709.

Ferris, T. A., I. L. Mao, and C. R. Anderson. 1985. Selecting for lactation curve and milk yield in dairy cattle. J. Dairy Sci. 68:1438-1448.

Fourichon, C., H. Seegers, and X. Malher. 2000. Effect of disease on reproduction in the dairy cow: A meta-analysis. Theriogenology 53:1729-1759.

Freeze, B. S., and T. J. Richards. 1992. Lactation curve estimation for use in economic optimization models in the dairy industry. J. Dairy Sci. 75:2984-2989.

Fuquay, J., A. Zook, and W. Poe. 1975. Metabolic and physiologic response of dairy cattle to coliform mastitis. J. Dairy Sci. 58:751-752.

Gomes, M. G., L. J. White, and G. F. Medley. 2004. Infection, reinfection, and vaccination under suboptimal immune protection: Epidemiological perspectives. J. Theor. Biol. 228:539-549.

González, R. N., J. S. Cullor, D. E. Jasper, T. B. Farver, R. B. Bushnell, and M. N. Oliver. 1989. Prevention of clinical coliform mastitis in dairy cows by a mutant Escherichia coli vaccine. Can. J. Vet. Res. 53:301-305.

González, R. N., D. J. Wilson, H. O. Mohammed, P. M. Sears, A. L. Rivas, and S. G. Campbell. 1996. A placebo-controlled trial of an Escherichia coli J5 bacterin and the ribotyping-based assessment of coliform bacteria diversity on a dairy farm. Pages 277-280 in Proc. 19th World Buiatr. Cong., Edinburgh, UK. Br. Cattle Vet. Assoc., Gloucestershire, UK.

Jackson, E., and J. Bramley. 1983. Coliform mastitis. In Pract. 5:135-146.

Jones, G. F., and G. E. Ward. 1989. Cause, occurrence, and clinical signs of mastitis and anorexia in cows in a Wisconsin study. J. Am. Vet. Med. Assoc. 195:1108-1113.

Macmillan, K. L., I. J. Lean, and C. T. Westwood. 1996. The effects of lactation on the fertility of dairy cows. Aust. Vet. J. 73:141147. 
Maizon, D. O., P. A. Oltenacu, Y. T. Grohn, R. L. Strawderman, and U. Emanuelson. 2004. Effects of diseases on reproductive performance in Swedish Red and White dairy cattle. Prev. Vet. Med. 66:113-126.

Rajala-Schultz, P. J., Y. T. Grohn, C. E. McCulloch, and C. L. Guard. 1999. Effects of clinical mastitis on milk yield in dairy cows. J. Dairy Sci. 82:1213-1220.

Santos, J. E., R. L. Cerri, M. A. Ballou, G. E. Higginbotham, and J. H. Kirk. 2004. Effect of timing of first clinical mastitis occurrence on lactational and reproductive performance of Holstein dairy cows. Anim. Reprod. Sci. 80:31-45.

Schaeffer, L. R., J. Jamrozik, G. J. Kistemaker, and B. J. Van Doormaal. 2000. Experience with a test-day model. J. Dairy Sci. 83:1135-1144.

Schrick, F. N., M. E. Hockett, A. M. Saxton, M. J. Lewis, H. H. Dowlen, and S. P. Oliver. 2001. Influence of subclinical mastitis during early lactation on reproductive parameters. J. Dairy Sci. 84:1407-1412.

Suzuki, C., K. Yoshioka, S. Iwamura, and H. Hirose. 2001. Endotoxin induces delayed ovulation following endocrine aberration during the proestrous phase in Holstein heifers. Domest. Anim. Endocrinol. 20:267-278.

Vandeputte-Van Messom, G., C. Burvenich, E. Roets, A. M. MassartLeen, R. Heyneman, W. D. Kremer, and A. Brand. 1993. Classification of newly calved cows into moderate and severe responders to experimentally induced Escherichia coli mastitis. J. Dairy Res. 60:19-29.

Wagter, L. C., B. A. Mallard, B. N. Wilkie, K. E. Leslie, P. J. Boettcher, and J. C. Dekkers. 2000. A quantitative approach to classifying Holstein cows based on antibody responsiveness and its relationship to peripartum mastitis occurrence. J. Dairy Sci. 83:488-498.
Wendt, K., and H. Stellmacher. 1996. Infectious burdens of reproduction of female dogs. Tierarztl. Prax. 24:79-84.

Wenz, J. R., G. M. Barrington, F. B. Garry, K. D. McSweeney, R. P. Dinsmore, G. Goodell, and R. J. Callan. 2001. Bacteremia associated with naturally occurring acute coliform mastitis in dairy cows. J. Am. Vet. Med. Assoc. 219:976-981.

Wilson, D. J., P. C. Bartlett, J. H. Kirk, R. W. Mellenberger, and E. C. Mather. 1991a. N-acetyl-beta-D-glucosaminidase as a predictor of milk loss and recovery after clinical mastitis. Am. J. Vet. Res. $52: 1110-1116$.

Wilson, D. J., R. N. González, and H. H. Das. 1997. Bovine mastitis pathogens in New York and Pennsylvania: Prevalence and effects on somatic cell count and milk production. J. Dairy Sci. 80:2592-2598.

Wilson, D. J., R. N. González, J. Hertl, H. F. Schulte, G. J. Bennett, Y. H. Schukken, and Y. T. Grohn. 2004. Effect of clinical mastitis on the lactation curve: A mixed model estimation using daily milk weights. J. Dairy Sci. 87:2073-2084.

Wilson, D. J., Y. T. Grohn, G. J. Bennett, R. N. González, Y. H. Schukken, and J. Spatz. 2007. Comparison of J5 vaccinates and controls for incidence, etiologic agent, clinical severity, and survival in the herd following naturally occurring cases of clinical mastitis. J. Dairy Sci. 90:4282-4288.

Wilson, D. J., P. S. Herer, and P. M. Sears. 1991b. N-acetyl-beta-Dglucosaminidase, etiologic agent, and duration of clinical signs for sequential episodes of chronic clinical mastitis in dairy cows. J. Dairy Sci. 74:1539-1543.

Zwald, N. R., K. A. Weigel, Y. M. Chang, R. D. Welper, and J. S. Clay. 2004. Genetic selection for health traits using producer-recorded data. I. Incidence rates, heritability estimates, and sire breeding values. J. Dairy Sci. 87:4287-4294. 